\title{
Q ualidade fisiológica de sementes de pitangueira submetidas a diferentes procedimentos de secagem e substratos - Parte 1
}

\author{
Lúcia H. de M. Sena ${ }^{1}$, Valderez P. Matos ${ }^{1}$, Elane G. B. de S. Ferreira ${ }^{2}$, Anna G. de F. A. Sales ${ }^{2} \&$ Mauro V. Pacheco ${ }^{3}$
}

\begin{abstract}
RESUMO
Propôs-se, no presente trabalho, determinar o procedimento de secagem e substratos ideais para avaliar a viabilidade e o vigor de sementes de pitangueira (Eugenia uniflora L.). 0 delineamento experimental adotado foi o inteiramente casualizado, em arranjo fatorial $2 \times 4$ (2 procedimentos de secagem: à sombra e ao sol; 4 substratos: Areia, vermiculita, pó-de-coco e papel toalha) com quatro repetições de 25 sementes cada uma. Caracterizou-se a curva de absorção de água pela semente e se avaliaram os seguintes parâmetros: germinação (\%), primeira contagem de germinação (\%), índice de velocidade de germinação e sementes mortas (\%). 0 experimento foi conduzido em germinador do tipo BOD, regulado a temperatura constante de $25^{\circ} \mathrm{C}$ e regime de luz contínua. Nas condições em que o trabalho foi realizado, a secagem à sombra e 0 substrato vermiculita podem ser recomendados para avaliar a qualidade fisiológica, porque proporcionaram maior germinação e desenvolvimento inicial das plântulas de pitangueira.
\end{abstract}

Palavras-chave: Eugenia uniflora, semente recalcitrante, curva de embebição, germinação

\section{Physiological quality of surinam cherry seeds submitted to different procedures of drying and substrates - Part 1}

\begin{abstract}
The present work had as its objective to determine the ideal procedure of drying and the substrate to evaluate the viability and vigour of surinam cherry seeds (Eugenia uniflora L.). The experiment was developed in a completely randomized design in factorial scheme $2 \times 4$ (2 procedures of drying: shade and sun; 4 substrates: sand, vermiculite, coconut fiber and paper towels) with four replications of 25 seeds each. The water absortion curve was characterized and the following parameters were analyzed: germination percentage, first germination count (\%), germination speed index and dead seeds (\%). The experiment was conducted in a BOD germinator regulated at constant temperature of $25 \stackrel{\circ}{\circ}$ and regime of continuous light. In the conditions where the work was carried out, the drying under shade and vermiculite may be recommended to evaluate the vigour because they provided the best germination and initial development of surinam cherry seedlings.
\end{abstract}

Key words: Eugenia uniflora, recalcitrant seed, water imbibition curve, germination

\footnotetext{
1 DEPA/UFRPE, Rua Dom Manoel de Medeiros s.n., Dois Irmãos, CEP 52171-900, Recife, PE. Fone (081) 3320-6250. E-mail (s): Iu_cia_@hotmail.com; vpmatos@ig.com.br

2 DCFL/UFRPE. E-mail (s): egbsf@bol.com.br; seedsannaballet@yahoo.com.br

${ }_{3}^{3}$ DAP/U FRN, Av. Senador Salgado Filho, s/n, Campus Universitário, CEP 59092-970, Natal, RN. Fone (84) 3225-3700. E-mail: pachecomv@ufrnet.br
} 


\section{INTRODUÇÃO}

A pitangueira (Eugenia uniflora L. Myrtaceae) é uma fruteira nativa do Brasil adaptada às condições climáticas do Nordeste e encontrada em todo o território nacional (Abreu et al., 2005). Em Pernambuco, a maior parte da produção do fruto provém de pequenos pomares domésticos, localizados no Grande Recife e em outros municípios da Zona da Mata e Agreste Meridional; entretanto, vários pequenos produtores têm demonstrado interesse em explorar comercialmente a pitangueira devido ao crescente consumo do fruto (Melo et al., 2000), de sabor exótico, o que lhe confere grandes perspectivas de utilização e crescimento no mercado interno e externo (Glass, 1997).

A E. uniflora L. é utilizada no paisagismo ou cultivada em pomares domésticos, sendo sua madeira empregada na confecção de cabos de ferramentas e outros instrumentos agrícolas (Lorenzi, 1998). Os frutos contêm cálcio, fósforo e vitamina C (Silva, 2006), dos quais se pode produzir geléias, doces, refrescos, sorvetes, licores e vinhos de qualidade apreciável (Scalon et al., 2001) ou utilizá-los como aditivos em bebidas lácteas (Guimarães et al., 1982), na forma de refresco em pó (Alexandre et al., 2007) ou in natura. A atividade farmacológica desta espécie refere-se a aspectos de toxicidade aguda, diminuição da propulsão intestinal e dos níveis da pressão sanguínea (Auricchio \& Bacchi, 2003), além de ser fonte promissora de compostos antioxidantes (Lima et al., 2002).

Existem vários métodos para secar as sementes colhidas mas todos visam à obtenção de sementes que, quando semeadas, germinem e originem plântulas vigorosas (Carvalho \& Nakagawa, 2000). Na secagem natural as sementes são secadas essencialmente pela ação do calor e do vento, sem o uso de equipamento mecânico e/ou eletroeletrônico; mais barata e mais lenta que a artificial, sujeita, portanto, às modificações climáticas, razão pela qual é utilizada principalmente nas pequenas propriedades (Carvalho, 2005).

Dentro da tecnologia e análise de sementes, o teste de germinação é o suporte para todas as outras análises no qual se deduz a importância do conhecimento das estruturas essenciais das plântulas para uma interpretação correta dos parâmetros avaliados (Oliveira, 1993), podendo-se identificar plântulas normais que, em condições de campo originarão, seguramente, plantas vigorosas e produtivas.

De acordo com as prescrições das Regras para Análise de Sementes (Brasil, 1992) além da luz, temperatura, água e oxigênio, a escolha do substrato tem fundamental importância nos resultados do teste padrão de germinação. Embora não sejam prescritos em Brasil (1992), a vermiculita e o pó-de-coco vêm sendo usados com bons resultados para sementes de algumas espécies florestais e frutíferas (Figliola et al., 1993; Lopes et al., 2005; Azeredo et al., 2006; Pacheco et al., 2006; Lima et al., 2007; Pacheco et al., 2007).

Neves (1994) afirma que a pitangueira e outras espécies do gênero Eugenia, apresentam comportamento semelhante ao de sementes recalcitrantes. Essas sementes são sensíveis à desidratação e não passam pela fase de dessecação no processo de maturação, sendo dispersas com grau de umidade relativamente alto (Berjak \& Pammenter, 2000).
Embora a pitangueira apresente grande potencial econômico de exploração para a fruticultura do Nordeste, as pesquisas dirigidas à cultura são muito escassas (Bezerra et al., 2004); é fundamental, portanto, que as sementes manifestem germinação rápida e homogênea para que se obtenha uniformidade em tamanho e menor tempo na formação de mudas. Objetivou-se, desta forma, com o presente trabalho, determinar o procedimento de secagem para obtenção de sementes de alta qualidade e os substratos ideais para avaliação segura da viabilidade e vigor de sementes de pitangueira.

\section{MATERIAL E MÉTODOS}

Os frutos da pitangueira (Eugenia uniflora L.), fisiologicamente desenvolvidos, foram coletados de árvores pertencentes a um pequeno produtor, localizado no município de Bonito, Pernambuco, PE, em setembro de 2006; em seguida, foram conduzidos ao Laboratório de Sementes do Departamento de Agronomia da Universidade Federal Rural de Pernambuco (UFRPE), onde foram despolpados manualmente e as sementes postas para secar sobre tecido de algodão, eliminando-se as sementes imaturas, deterioradas ou danificadas por insetos.

As sementes foram secadas à sombra e ao sol, durante 72 h. As secadas a pleno sol foram expostas pela manhã e à tarde ao calor, à noite recolhidas e cobertas com a finalidade de facilitar a difusão da umidade interna para a parte externa da semente, bem como das sementes mais úmidas para as mais secas, o que resulta em secagem mais homogênea, segundo Carvalho \& Nakagawa (2000). Efetuou-se a secagem à sombra deixando-se as sementes em local com sombra, durante $72 \mathrm{~h}$.

Em ambos os procedimento e à medida em que se processou a secagem, as sementes foram constantemente revolvidas a fim de propiciar melhor aeração em toda a massa de sementes e secagem mais uniforme; nesta ocasião, a temperatura média atingida durante as $72 \mathrm{~h}$ de secagem à sombra foi de $27,5^{\circ} \mathrm{C}$ e ao sol $34^{\circ} \mathrm{C}$.

As sementes foram armazenadas em recipientes de vidro com tampas vedadas durante três meses, em ambiente de laboratório. Após este período se determinou o teor de água apresentado pelas sementes, segundo Brasil (1992), utilizando-se duas repetições de 50 sementes cada uma; as sementes submetidas a secagem à sombra apresentaram teor médio de água de $47 \%$ enquanto as submetidas a secagem ao sol indicaram $45 \%$.

Antes da instalação do teste de germinação as sementes foram desinfestadas com uma solução de hipoclorito de sódio a $5 \%$, durante $5 \mathrm{~min}$ e, em seguida, lavadas com água deionizada.

A semeadura ocorreu entre os substratos areia, vermiculita fina, pó-de-coco e papel toalha. Os três primeiros substratos foram previamente autoclavados, permanecendo $2 \mathrm{~h}$ em aquecimento a $120^{\circ} \mathrm{C}$, e em seguida postos para secar e colocados em caixas plásticas transparentes de $11 \times 11 \times 3 \mathrm{~cm}$, com tampa (gerbox) e umedecidos com solução de Nistatina a $0,2 \%$, adotando-se $60 \%$ da capacidade de retenção de água 
do substrato. Com relação ao substrato papel toalha, este foi umedecido com a mesma solução dos outros substratos, na proporção de 3 vezes o peso do papel e organizado em forma de rolo, segundo prescrições de Vieira \& Carvalho (1994).

O experimento foi conduzido em germinador do tipo Biochemical Oxigen Demand (BOD), regulado a temperatura constante de $25^{\circ} \mathrm{C}$ e regime de luz contínua, utilizando-se quatro lâmpadas fluorescentes de $20 \mathrm{~W}$, tipo luz do dia.

O número de sementes germinadas foi avaliado diariamente adotando-se, como critério de germinação, o surgimento do epicótilo que, segundo Oliveira (1993) é a porção do eixo ascendente da plântula compreendida entre o ponto de união dos cotilédones e o da primeira folha ou par de folhas.

A curva de embebição foi caracterizada através da pesagem inicial de quatro repetições de 25 sementes para cada procedimento de secagem; a seguir, foram semeadas em papel toalha, umedecidas com água deionizada na proporção de 3 vezes o peso do papel, organizados em forma de rolo e conduzidos ao germinador do tipo BOD, regulado a mesma temperatura e luz do teste de germinação. As sementes foram pesadas em balança analítica com precisão de $0,01 \mathrm{~g}$ após 1 , 2, 3, 4, 5, 6, 7, 8, 9 e 10 h de embebição e a partir daí a cada 24 h, até completar $72 \mathrm{~h}$ de embebição, sendo a cada pesagem secadas superficialmente com papel absorvente e, posteriormente, recolocadas nos seus devidos rolos. Com os valores das porcentagens consecutivas calculou-se a porcentagem de ganho de água em relação ao peso inicial das sementes a fim de se estabelecer a curva de embebição.

Avaliaram-se, também, os seguintes parâmetros: porcentagem de germinação: correspondeu à porcentagem total de sementes germinadas até o $87^{\circ}$ dia após a semeadura; primeira contagem de germinação: porcentagem de sementes germinadas no período de ocorrência das primeiras plântulas normais ao $23^{\circ}$ dia após a semeadura; índice de velocidade de germinação (IVG): determinado de acordo com a fórmula apresentada por Maguire (1962) e porcentagem de sementes mortas: calculada em conjunto com o teste de germinação, considerando-se as sementes mortas no final do teste.

$\mathrm{O}$ delineamento experimental utilizado foi o inteiramente casualizado, sendo os tratamentos distribuídos em arranjo fatorial $2 \times 4$ (dois procedimentos de secagem e quatro substratos), com quatro repetições de 25 sementes cada uma; para a análise dos dados foi utilizado o software estatístico ESTAT, versão 2 (ESTAT, 1994) desenvolvido pela FCAV/UNESP, Jaboticabal, SP. As médias foram comparadas pelo teste de Tukey a $5 \%$ de probabilidade e os dados em porcentagem foram transformados em arc sen $(\mathrm{x} / 100)^{0,5}$.

\section{RESULTADOS E DISCUSSÃO}

Na Figura 1 se apresenta a curva de embebição das sementes de Eugenia uniflora L., submetidas aos procedimentos de secagem à sombra e ao sol. Verificou-se, de acordo com os resultados, que a porcentagem de ganho de água em relação ao peso inicial das sementes aumentou gradativamente com o aumento do período de embebição.

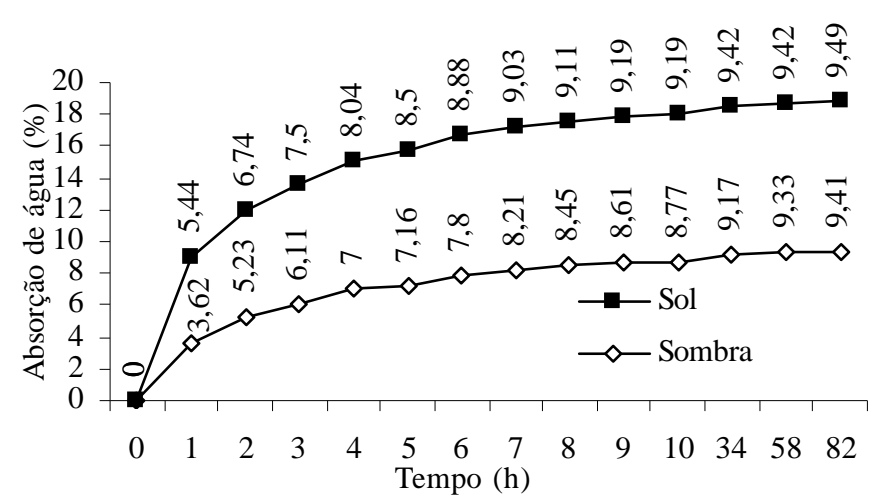

Figura 1. Curva de embebição (\%) das sementes de pitangueira (Eugenia uniflora L.) submetidas a diferentes procedimentos de secagem

Para as sementes secadas ao sol (Figura 1) ocorreu uma embebição rápida na primeira hora, alcançada em porcentual $33,46 \%$ maior em relação às secadas à sombra; entretanto, a absorção foi maior e mais rápida nas primeiras $10 \mathrm{~h}$ de embebição sugerindo o padrão trifásico de absorção de água pelas sementes (Bewley \& Black, 1994). Nos períodos de embebição posteriores, a absorção de água ocorreu lentamente não proporcionando aumento significativo do ganho de água em relação ao peso inicial das sementes; deste modo, não foi possível caracterizar a segunda fase da embebição.

$\mathrm{Na}$ avaliação da qualidade fisiológica das sementes em função dos dois procedimentos de secagem e substratos, não houve efeito significativo da interação entre procedimentos de secagem e substratos para a porcentagem de germinação mas foi constatado efeito significativo apenas para os procedimentos de secagem (Figura 2A), de vez que as sementes submetidas ao procedimento de secagem à sombra apresentaram maior germinação $(85,70 \%)$ quando comparadas com aquelas secadas ao sol $(52,50 \%)$.

Em relação ao vigor, os resultados obtidos na Figura $2 \mathrm{~B}$ indicaram que na primeira contagem de germinação, realizada no $27^{\circ}$ dia, as sementes submetidas ao procedimento de secagem à sombra apresentaram maiores resultados, quando comparadas com as secadas ao sol.

Pode-se observar, na Figura 2B, que as sementes secadas ao sol não apresentaram diferença estatística entre os substratos, diferentemente do que foi observado nas sementes secadas à sombra em que o substrato vermiculita $(32,29 \%)$ ocasionou germinação inicial mais rápida.

Ao se realizar a primeira contagem das plântulas também se realiza, embora indiretamente, uma avaliação da velocidade de germinação, indício de que maior porcentagem na primeira contagem significa que as sementes germinaram mais rapidamente (Vieira \& Carvalho, 1994).

Quanto ao índice de velocidade de germinação (Figura 2C) constatou-se que a secagem à sombra $(0,69)$ foi o melhor procedimento de secagem obtendo-se valores aproximadamente duas vezes maiores do que o procedimento de secagem ao sol $(0,25)$; além disso, ao relacionar os dois procedimentos de secagem, observa-se decréscimo de $65 \%$ na velocidade de germinação das sementes submetidas à secagem ao sol.

$\mathrm{O}$ substrato vermiculita $(0,62)$ foi aquele que proporcionou germinação mais rápida às sementes de pitangueira (Fi- 
A.

$\begin{array}{lll}\text { Sombra } & \square \text { Sol } & \text { 冒 Areia } \\ \text { Vermiculita } & \text { 皿 Pó-de-coco } & \text { 罗 Papel toalha }\end{array}$

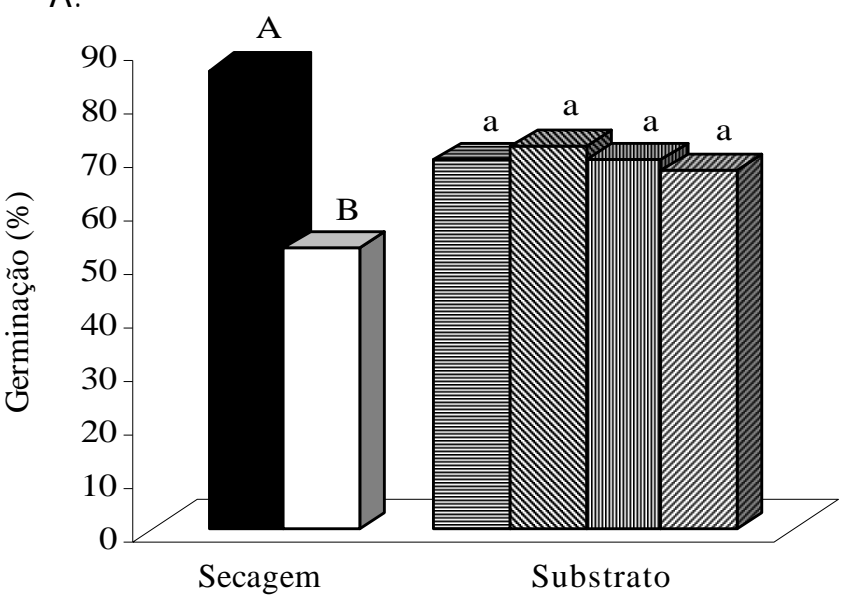

口 Sombra $\square$ Sol 目 Areia

$\mathbb{N}$ Vermiculita 四 Pó-de-coco Papel toalha

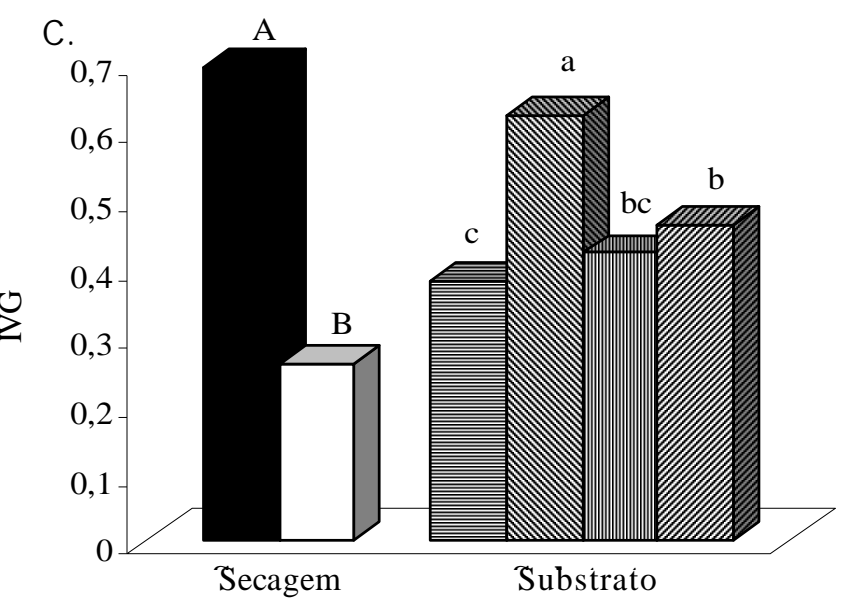

目 Areia $\mathbb{Q}$ Vermiculita 皿 Pó-de-coco $\mathbf{0}$ Papel toalha

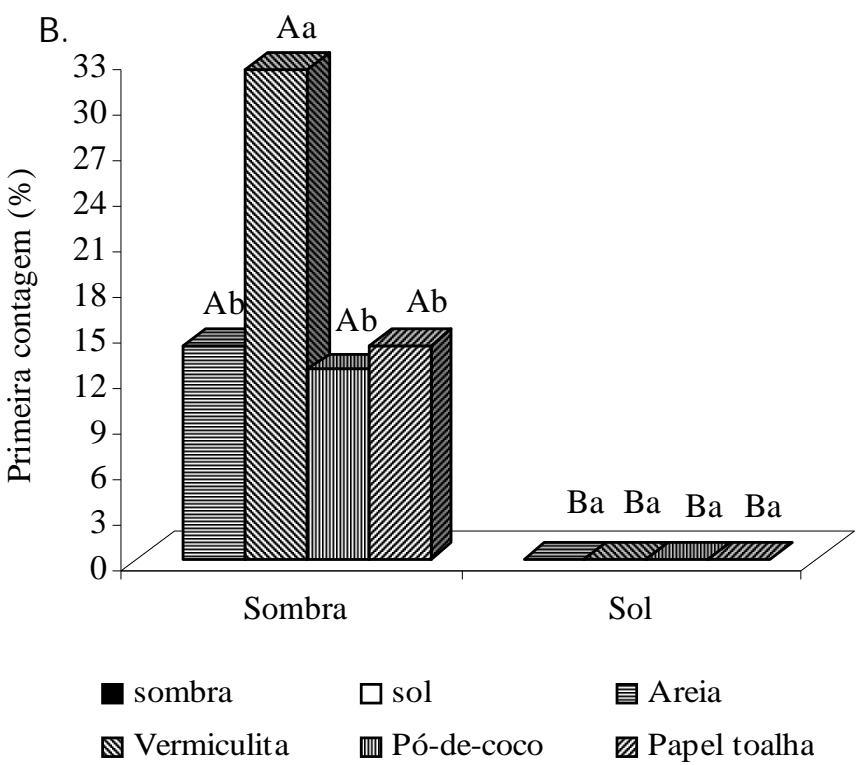

D.

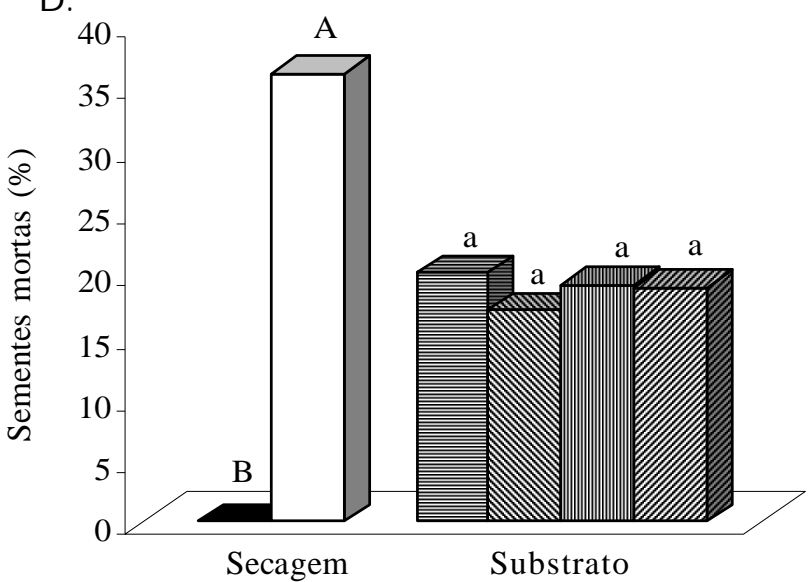

Obs.; Médias seguidas da mesma letra maiúscula (para método de secagem) e minúscula (para substratos), não diferem entre si pelo teste de Tukey a $5 \%$ de probabilidade

Figura 2. Teste de germinação e vigor em sementes de Eugenia uniflora L. submetidas a diferentes procedimentos de secagem e substratos. A - Germinação (\%) $(C V=7,51 \%) ; B$ - Primeira contagem de germinação (\%) (CV = 55,70\%); C - Índice de velocidade de germinação (IVG) (CV = 11,32\%); D - Sementes mortas (\%) $(\mathrm{CV}=16,65 \%)$

gura 2C); já os substratos pó-de-coco $(0,42)$ e papel toalha $(0,46)$ não diferiram entre si. Com relação ao substrato areia $(0,38)$, as sementes germinaram mais lentamente em comparação com aquelas semeadas em substrato vermiculita ocasionando redução de $39 \%$ na sua velocidade de germinação.

A redução da porcentagem, velocidade de germinação e emergência de plântulas, é uma das sequências da interação do potencial fisiológico das sementes com as condições do ambiente (Marcos Filho, 2005).

De acordo com os dados da Figura 2D, houve efeito significativo apenas entre os procedimentos de secagem. As sementes de pitangueira submetidas ao procedimento de secagem ao sol resultaram em maior porcentagem de sementes mortas $(36,05 \%)$ quando comparadas com as sementes secadas à sombra $(0 \%)$. Pode-se observar que o procedimento de secagem à sombra não induziu as sementes à morte, uma vez que sua porcentagem de germinação foi $38,74 \%$ maior que a do sol e as suas sementes permaneceram com teor de água mais elevado (47\%), o que pode ter ocasionado menor velocidade de deterioração das sementes já que se trata de semente recalcitrante.

Uma vez coletados, os frutos devem ser despolpados e as sementes postas para secar, beneficiadas e armazenadas adequadamente para que não percam seu poder germinativo em curto espaço de tempo (Paiva \& Gonçalves, 2001). Existem espécies para as quais não se aplica a regra geral de redução do teor de água das sementes e da temperatura de armazenamento e cujo período de viabilidade é bem mais curto (Neves, 1994), sendo classificadas como recalcitrantes (Roberts, 1973). Deste modo, as sementes de pitangueira secadas ao sol com teor de água de $45 \%$ apresentaram menor viabilidade e vigor, sendo a secagem à sombra na qual o teor de água das sementes foi de $47 \%$, indicada para as sementes de pitangueira.

As sementes recalcitrantes não podem ter sua água removida a níveis que permitam a quase completa redução do metabolismo; há, porém, uma faixa de hidratação na qual o 
metabolismo pode acarretar danos mais acentuados que aqueles que ocorrem em sementes com teores de água mais elevados (Marcos Filho, 2005). Segundo o autor, essas sementes são muito sensíveis à dessecação, mantendo o teor de água de 30 a 70\%; já Delgado (2006) afirma que sementes de espécies do gênero Eugenia apresentam valores de teores de água iniciais considerados altos, em torno de 40 a $70 \%$.

Este comportamento de redução na germinação e no vigor das sementes de pitangueira, observado quando o teor de água foi reduzido para $45 \%$ naquelas secadas ao sol, ocorreu porque, segundo Delgado (2006), as espécies do gênero Eugenia são sensíveis à dessecação, fato observado através da porcentagem de germinação (Figura 2A) apresentando decréscimo de $39 \%$ do procedimento de secagem à sombra para o do sol e da primeira contagem de germinação (Figura 2B), uma vez que não ocorreu germinação das sementes submetidas ao procedimento de secagem ao sol para todos os substratos, demonstrando o efeito recalcitrante desta semente que, ao reduzir em $2 \%$ o seu teor de água, ocasionou redução na velocidade de germinação (Figura 2C), mostrando início de deterioração nas sementes.

Aparentemente, os efeitos da secagem em temperaturas mais elevadas podem não ser imediatos, pois somente após algum tempo de armazenamento é que esses efeitos se tornam mensuráveis (Afonso Júnior \& Corrêa, 2000) ocasionando, muitas vezes, reduções no vigor e na emergência em campo (Peske \& Villela, 2005). A citação acima justifica os resultados obtidos uma vez que as sementes expostas ao sol apresentaram desempenho germinativo inferior ao das sementes expostas à secagem à sombra.

O teor de água é um dos fatores determinantes do comportamento das sementes recalcitrantes e o conhecimento dos teores críticos e letal de água de uma espécie é indispensável para o planejamento e a execução da secagem e do armazenamento das sementes (Martins et al., 1999). A deterioração, em muitos casos imperceptível na fase inicial, se manifesta no decorrer do tempo ocasionando reflexos negativos no vigor (Garcia et al., 2004); sendo assim, licos e de membrana, resultando no insecagem causaria a alteraçalcitrantes e o conhecimento dos teores cr os resultados obtidos evidenciaram uma significante relação entre a redução do teor de água e a perda da viabilidade e vigor das sementes de pitangueira.

A escolha do substrato é muito importante para obtenção de melhores resultados em um teste de germinação, em vista, sobretudo, da grande variação que existe entre as espécies com relação ao substrato mais adequado (Alvino \& Rayol, 2007). Para as sementes de pitangueira, o substrato que melhor favoreceu a germinação foi a vermiculita e este resultado certamente foi obtido porque o substrato vermiculita apresenta boa capacidade de absorção (Figliolia et al., 1993), e não exige reumedecimento diário, são leves e de fácil manuseio ( $\mathrm{Pa}-$ checo et al., 2006).

De acordo com Fanti \& Perez (1999) a vermiculita também apresentou boas condições para a condução dos testes germinativos em sementes de olho de dragão (Adenanthera pavonina L.). Do mesmo modo, Andrade et al. (1999), com sementes de palmiteiro (Euterpe edulis Mart.) e Silva \& Aguiar (2004) com sementes de faveleira (Cnidosculus phyllacanthus
Pax \& K. Hoffm.) por proporcionar melhores resultados de germinação e vigor para esta espécie.

A capacidade de retenção de água e a quantidade de luz que o substrato permite chegar às sementes, podem ser responsáveis por diferentes respostas obtidas até quando se utiliza a mesma temperatura (Figliolia et al., 1993). Do mesmo modo, consta nas Regras para Análise de Sementes (Brasil, 1992) que se deve evitar, sempre que possível, o reumedecimento dos substratos após a semeadura, uma vez que pode causar variações adicionais aos resultados.

Existem poucas pesquisas nas quais se utilizam meios naturais para secagem das sementes; entretanto, sementes de umbu (Spondias tuberosa Arr Câm) (Araújo et al., 2001), araçá (Cisneiros et al., 2003), cagaiteira (Eugenia dysenterica DC.) (Nietsche et al., 2004), maracujá (Passiflora spp.) (Lima et al., 2006), pinha (Annona squamosa L.) (Wagner Júnior et al., 2006) e jenipapo (Genipa americana L.) (Prado Neto et al., 2007) foram secadas à sombra nos referidos trabalhos.

Neste sentido, a contribuição deste trabalho se torna significativa visto que se utiliza uma metodologia simples de ser aplicada, de baixo custo e sem necessidade de conhecimentos científicos complexos para a sua aplicação; desta forma, referida metodologia pode ser utilizada com segurança pelos pequenos produtores garantindo resultados favoráveis na germinação e desenvolvimento de plântulas de pitangueira e, consequentemente, possibilitando a obtenção do estande inicial desejado para a produção de mudas.

\section{CONCLUSÕES}

1. A secagem à sombra é recomendada para sementes de pitangueira.

2. O substrato vermiculita favoreceu a germinação e o desenvolvimento das plântulas de pitangueira podendo ser indicado para testes de germinação e vigor.

\section{LITERATURA CITADA}

Abreu, N. A. A.; Mendonça, V.; Ferreira, B. G.; Teixeira, G. A.; Souza, H. A.; Ramos, J. D. Crescimento de mudas de pitangueira (Eugenia uniflora L.) em substratos com utilização de superfosfato simples. Ciência e Agrotecnologia, v.29, n.6, p.1117-1124, 2005.

Afonso Júnior, P. C.; Corrêa, P. C. Efeitos imediato e latente da secagem de sementes de feijão colhidas com diferentes níveis de umidade. Ciência e Agrotecnologia, v.24, n.especial, p.33-40, 2000.

Alexandre, H. V.; Figueirêdo, R. M. F.de; Queiroz, A. J. de M. . Isotermas de adsorção de umidade da pitanga em pó. Revista de Biologia e Ciência da Terra, v.7, n.1, p.11-20, 2007.

Alvino, F. O.; Rayol, B. P. Efeito de diferentes substratos na germinação de Ochroma pyramidale (Cav. ex Lam.) Urb. Bombacaceae. Ciência Florestal, v.17, n.1, p.71-75, 2007.

Andrade, A. C. S.; Loureiro, M. B.; Souza, A. D. O.; Ramos, F. N.; Cruz, A.P. M. Reavaliação do efeito do substrato e da temperatura na germinação de sementes de palmiteiro (Euterpe edulis Mart.). Revista Árvore, v.23, n.3, p.279283, 1999. 
Araújo, F. P.; Santos, C. A.; Cavalcante, N. B.; Rezende, G. M. Influência do período de armazenamento das sementes de umbuzeiro na sua germinação e no desenvolvimento da plântula. Revista Brasileira de Armazenamento, v.26, n.2, p.36-39, 2001.

Auricchio, M. T.; Bacchi, E. M. Folhas de Eugenia uniflora L. (pitanga): Propriedades farmacobotânicas, químicas e farmacológicas. Revista Instituto Adolfo Lutz, v.62, n.1, p.55-61, 2003.

Azeredo, G. A.; Matos, V. P.; Lima, A. A.; Guedes, A. S.; Medeiros, A. Viabilidade de sementes de acerola (Malpighia punicifolia DC) influenciada pelo substrato, temperatura e coloração de frutos. Pesquisa Agropecuária Tropical, v.36, n.1, p.7-11, 2006.

Berjak, P.; Pammenter, N. W. What ultrastructure has told us about recalcitrant seeds. Revista Brasileira de Fisiologia Vegetal, v.12, n. especial, p.22-25, 2000.

Bewley, J. D.; Black, M. Seeds physiology of development and germination. New York: Plenum Press, 1994. 445p.

Bezerra, J. E. F.; Lederman, I. E.; Silva Júnior, J. F.; Alves, M. A. Comportamento da pitangueira (Eugenia uniflora L.) sob irrigação na região do Vale do Rio Moxotó, Pernambuco. Revista Brasileira de Fruticultura, v.26, n.1, p.177-179, 2004.

Brasil. Ministério da Agricultura e Reforma Agrária. Regras para análise de sementes. Brasília: Departamento Nacional de Produção Vegetal, 1992. 365p.

Carvalho, N. M. Métodos de secagem de sementes. In: A secagem das sementes. Jaboticabal: FUNEP, 2005. cap.3, p.67-169.

Carvalho, N. M.; Nakagawa, J. Sementes: Ciência, tecnologia e produção. Jaboticabal: FUNEP, 2000. 588p.

Cisneiros, R. A.; Matos, V. P.; Lemos, M. A.; Reis, O. V.; Queiroz, R. M. Qualidade fisiológica de sementes de araçazeiro durante o armazenamento. Revista Brasileira de Engenharia Agrícola e Ambiental, v.7, n.3, p.513-518, 2003.

Delgado, L. F. Tolerância à dessecação em sementes de espécies brasileiras de Eugenia. São Paulo: Instituto de Botânica da Secretaria do Meio Ambiente, 2006. 106p. Dissertação Mestrado

ESTAT - Sistema de Análise Estatística (ESTAT 2.0). Jaboticabal: Pólo Computacional do Departamento de Ciências Exatas da UNESP, 1994.

Fanti, A. C.; Perez, S. C. J. G. A. Influência do substrato e do envelhecimento acelerado na germinação de olho-de-dragão (Adenanthera pavonina L. (Fabaceae). Revista Brasileira de Sementes, v.21, n.2, p.135-141, 1999.

Figliola, M. B.; Oliveira, E. C.; Piña-Rodrigues, F. C. M. Análise de sementes. In: Aguiar, I. B.; Piña-Rodrigues, F. C. M.; Figliola, M. B. (Coord.). Sementes florestais tropicais. Brasília: ABRATES, 1993. p.137-174.

Garcia, D. C.; Barros, A. C. S. A.; Peske, S. T.; Menezes, N. L. A secagem de sementes. Ciência Rural, v.34, n.2, p.603608, 2004.

Glass, V. Pitangueira. Globo Rural, v.12, n.143, p.63-65, 1997.

Guimarães, F. A.; Holanda, L. F. F.; Maia, G. A. M.; Moura Fé, J. A. Tecnologia do néctar de pitanga (Eugenia uniflora L.). Ciência Agronômica, v.13, n.1/2, p.71-75, 1982.

Lima, A. A.; Caldas, R. C.; Santos, V. S. Germinação e crescimento de espécies de maracujá. Revista Brasileira de Fruticultura, v.28, n.1, p.125-127, 2006.
Lima, R. V.; Lopes, J. C.; Coelho, R. I. Germinação de sementes de urucu em diferentes temperaturas e substratos. Ciência e Agrotecnologia, v.31, n.4, p.1219-1224, 2007.

Lima, V. L. A. G.; Mélo, E. A.; Silva, D. E. Fenólicos e carotenóides totais em pitangueira. Scientia Agrícola, v.59, n.3, p.447-450, 2002.

Lopes, J. C.; Capucho, M. T.; Martins Filho, S.; Repossi, P. A. Influência da temperatura, substrato e luz na germinação de sementes de bertalha. Revista Brasileira de Sementes, v.27, n.2, p.18-24, 2005.

Lorenzi, H. Árvores brasileiras: Manual de identificação e cultivo de plantas arbóreas nativas do Brasil. Nova Odessa: Plantarum, 1998. 352p.

Maguire, J. D. Speed of germination-aid in selection and evoluation for seedlings emergence and vigor. Crop Science, v.2, n.1, p.176-177, 1962.

Marcos Filho, J. Fisiologia de sementes de plantas cultivadas. Piracicaba: FEALQ, 2005. 495p.

Martins, C. C.; Nakagawa, J.; Bovi, M. L. A. Tolerância à dessecação de sementes de palmito-vermelho (Euterpe espiritosantensis Fernandes). Revista Brasileira de Botânica, v.22, n.3, p.391-396, 1999.

Melo, E. A.; Lima, V. L. A. G.; Nascimento, P. P. Temperatura no armazenamento de pitanga. Scientia Agrícola, v.57, n.4, p.629634, 2000.

Neves, C. S. V. J. Sementes recalcitrantes. Pesquisa Agropecuária Brasileira, v.29, n.9, p.1459-1467, 1994.

Nietsche, S.; Gonçalves, V. D.; Pereira, M. C. T.; Santos, F. A.; Abreu, S. C.; Mota, W. F. Tamanho da semente e substratos na germinação e crescimento inicial de mudas de cagaiteira. Ciência e Agrotecnologia, v.28, n.6, p.1321-1325, 2004.

Oliveira, E. E. Morfologia de plântulas. In: Aguiar, I. B.; PiñaRodrigues, F. C. M.; Figliolia, M. B. Sementes florestais tropicais. Brasília: ABRATES, 1993. p.175-214.

Pacheco, M. V.; Matos, V. P.; Ferreira, R. L. C.; Feliciano, A. L. P.; Pinto, K. M. S. Efeito de temperaturas e substratos na germinação de sementes de Myracrodruon urundeuva Fr. All. (Anacardiaceae). Revista Árvore, v.30, n.3, p.359-367, 2006.

Pacheco, M. V.; Matos, V. P.; Ferreira, R. L. C.; Feliciano, A. L. P.; Pinto, K. M. S. Germinação de sementes de Apeiba tibourbou Aubl. em função de diferentes substratos e temperaturas. Scientia Florestalis, v.1, n.73, p.19-25, 2007.

Paiva, H. N.; Gonçalves, W. Insumos. In: Produção de mudas. Viçosa: Aprenda Fácil, 2001. cap.3, p.21-31. Coleção Jardinagem e Paisagismo. Série Arborização Urbana, v.1.

Peske, S. T.; Villela, F. A. Secagem de sementes. In: Peske, S. T.; Rosenthal, M. A.; Rota, G. R. M. Sementes: Fundamentos científicos e tecnológicos. Pelotas: UFPel, 2005. p.284-230.

Prado Neto, M.; Dantas, A. C. V. L.; Vieira, E. L.; Almeida, V. O. Germinação de sementes de jenipapeiro submetidas à pré-embebição em regulador e estimulante vegetal. Ciência e Agrotecnologia, v.31, n.3, p.693-698, 2007.

Roberts, E. H. Predicting the storage life of seed. Seed Science and Technology, v.1, n.3, p.499-514, 1973.

Scalon, S. P. Q.; Scalon Filho, H.; Rigoni, N. R.; Veraldo, F. Germinação e crescimento de mudas de pitangueira (Eugenia uniflora L.) sob condições de sombreamento. Revista Brasileira de Fruticultura, v.23, n.3, p.136-140, 2001. 
Silva, L. M. M.; Aguiar, I. B.; Efeito dos substratos e temperaturas na germinação de sementes de Cnidosculus phyllacanthus Pax \& K. Hoffm. (faveleira). Revista Brasileira de Sementes, v.26, n.1, p.9-14, 2004.

Silva, S. M. Pitanga. Revista Brasileira de Fruticultura, v.28, n.1, p.1-159, 2006.
Vieira, R. D.; Carvalho, N. M. Testes de vigor em sementes. Jaboticabal: FUNEP, 1994. 164p

Wagner Júnior, A.; Pimentel, L. D.; Negreiros, J. R. S.; Neres, C. R. L.; Alexandre, R. S.; Diniz, E. R.; Bruckner, C. H. Influência do tempo de embebição em água sobre a dormência de sementes de pinha (Annona squamosa L.). Revista Ceres, v.53, n.307, p.317-32, 2006. 